\title{
Fuzzy Multicriteria ABC Supplier Classification in Global Supply Chain
}

\author{
Petar Kefer, ${ }^{1}$ Dragan D. Milanovic, ${ }^{2}$ Mirjana Misita, ${ }^{2}$ and Aleksandar Zunjic ${ }^{2}$ \\ ${ }^{1}$ Omni Surfaces, 40 Kodiak Cres, Toronto, ON, Canada M3J 3G5 \\ ${ }^{2}$ Faculty of Mechanical Engineering, Kraljice Marije 16, 11000 Belgrade, Serbia \\ Correspondence should be addressed to Mirjana Misita; mmisita@mas.bg.ac.rs
}

Received 13 April 2016; Revised 5 July 2016; Accepted 19 July 2016

Academic Editor: Mónica A. López-Campos

Copyright (c) 2016 Petar Kefer et al. This is an open access article distributed under the Creative Commons Attribution License, which permits unrestricted use, distribution, and reproduction in any medium, provided the original work is properly cited.

\begin{abstract}
The determination of the optimal purchasing strategy in enterprise that is a part of global supply chain could be performed in two steps. In step one, a classification of potential suppliers is performed in order to determine the optimal portfolio of suppliers. This is delivered by using the fuzzy multicriteria proposed $\mathrm{ABC}$ classification method. Uncertainties in relative importance of criteria and their values are described by linguistic expressions. Modelling of linguistic expressions is based on the fuzzy sets theory. In the second step, ranking of optimal portfolio of suppliers is performed by using the modified ELECTRE method. The obtained results represent valuable input for determining the long time purchasing strategy and building partnership with the best suppliers. The developed two-step model is verified on real life data. The obtained results indicate good compliance with the opinions management in this type of industry. It is worth to mention that the proposed model can be easily extended and adopted to the analysis of other issues of management which could be applicable in different research areas.
\end{abstract}

\section{Introduction}

During the usual activities in enterprises, many products and services originated out of enterprise are used. In that manner, the organization should ensure that purchased and used products and services conform to specified requirements [1]. In compliance with that, an organization shall establish and apply criteria for evaluation, selection, and monitoring of performance and reevaluate suppliers (external providers). On the other hand, distribution and procurement, in the same time, are usually based on complex procedures, involving many management and control functions at various levels. Strategies for better supply management must promote an effective and appropriate products and services supply, providing products and services in requested quantities, just in time, and yet the inventory costs have to be as low as possible. Development of supply policy and appropriate strategy have to be defined on the enterprise level or on the level of the whole supply chain which is a complex problem.

Recent work majorly focuses on analytical and decision modelling [2] for supplier selection, as well as on supplier development [3]. Development of sophisticated models for optimal supplier selection strategy [4] for different kind of products requires time, effort, and resources which lead to an increase in inventory control costs and to an increase in total costs, too. In order to decrease inventory control costs, in practice, the first important step is to perform the classification of potential suppliers into classes in compliance with their ability to provide processes or products and services in accordance with specified requirements. Based on the suppliers classification results, management defines appropriate ways to manage and control specific suppliers and rank them for cooperation and building partner connections. Building partnership should be based on obtaining respect and trust with mutual benefit [5]

In practice, one of the widely used techniques for classification of different items into classes (applicable to the classification of suppliers, too) is the ABC method which is based on Pareto analysis [6]. This method is easy to understand and use in practice since, in the conventional $\mathrm{ABC}$ classification method, inventory items are divided into three classes A, $\mathrm{B}$, and $\mathrm{C}$. The values of deterministic classification criteria are classified into descending row. As it is known, $5-10 \%$ 
of analysed inventory items ranked at first place belong to group A, next $15 \%$ correspond to group B, and the rest of inventory items correspond to group C. Selection of the classification criterion depends on the kind of problem being considered. The issue of selection of suppliers may be stated as a multicriteria optimization task. In literature, there is a lot of papers that employ different methods for ranking and assessment of suppliers. The most used methods are Analytical Hierarchy Process (AHP) [7], Technique for Order of Preference by Similarity to Ideal Solution (TOPSIS) [8], ELimination Et Choix Traduisant la REalité (ELECTRE) [9], or combination of two or more methods [10]. In compliance with the rank of suppliers, decision makers may choose the most suitable suppliers work building partnership relations.

The conventional ABC methodology may sometimes not be appropriate to provide a good classification of inventory items in practice [11]. If there is a need to make the classification more sophisticated, more than one classification criterion and imprecise data about items have to be used. The classification task becomes a multicriteria classification problem in the presence of uncertainty.

In this paper, the authors focus on the supplier classification in global supply chain, where number of suppliers is large due to demands of global market. The number and types of the selection criteria are not clearly defined in the literature and there are no specific guidelines that treat this issue. The specificity of construction industry products, their variable demand over time and, in particular, high cost indicate the importance of suppliers' classification problem. A new fuzzy multicriteria ABC model for classification of suppliers in construction industry is proposed. Three eliminatory criteria are selected to make a base of potential suppliers: (1) customer care, (2) quality (ratio between price and specific performances of products), and (3) delivery method (ratio between costs and delivery rate).

The objective of paper is to define the appropriate purchasing strategy in the global supply chain through two steps: (1) classification of a large number of potential suppliers by applying proposed fuzzy multicriteria $\mathrm{ABC}$; (2) the ranking of classified A group of suppliers (optimal portfolio of suppliers) by using the proposed model consisted from fuzzy AHP and fuzzy ELECTRE methods. For the classification problem, the proposed fuzzy multicriteria $\mathrm{ABC}$ methodology is suitable since it treats uncertain criteria in appropriate way and it is easy and suitable for usage leading to determination of optimal portfolio of suppliers. This optimal portfolio of suppliers consisted of those who are suitable for further selection of the group that will be used for building partnership. The methods of multicriteria decision making methods, fuzzy AHP and fuzzy ELECTRE, are used for ranking of selected suppliers. In this manner, resources such as time and costs of defining appropriate supply strategy may be reduced significantly and in the same time, effectiveness of supply process is increased. In the final consequence, this should lead to increase effectiveness of all business processes in global supply chain.

Each of three considered criteria is described by using linguistic expressions specified by enterprise management team. These linguistic expressions are modelled using triangular fuzzy numbers by analogy to Aleksić et al., [12]. Uncertainty in criteria values used in supplier classification are modelled by fuzzy sets [13-15]. The motivation for using this methodology came from its suitability for handling imprecise and ambiguous data, and it supports usage of decision making methods which operate with such data. It may be said that fuzzy sets theory resembles the human reasoning in its use of approximate information and uncertainty to generate decisions [16]. In this manner, fuzzy sets have several advantages over theories that treat similar problems: (a) they are based on a natural language, (b) they are conceptually easy to understand, (c) they could be combined with conventional methods and techniques for dealing and reasoning with uncertain data, and (d) they can capture most nonlinear relations in problems of arbitrary complexity [17].

The paper is organized in the following way. The literature review is given in Section 2. Section 3 presents evaluation framework and modelling of uncertainties. In Section 4, the proposed algorithm is presented. Section 5 is used for the verification of the model using an illustrative example. Conclusions are presented in Section 6.

\section{Literature Review}

A number of papers presented in the literature were dealing with the problem of items classification in uncertain environments for inventory control purposes and proposed fuzzy multicriteria $\mathrm{ABC}$ classification approaches after realizing the importance of considering multiple criteria in the $\mathrm{ABC}$ analysis [18]. In addition to the overall cost, some other criteria, such as lead time, inventory holding cost, limitation of the warehouse space, and order cost, were recognized as being important for items classification.

In the literature, as well as in the practice, determination of the optimal portfolio of suppliers is based on mathematical models. Possibly, there may be a lot of potential suppliers so in the first step, the eliminatory criteria should be applied. Building partners' relations with suppliers should be performed after the portfolio of suitable suppliers is generated. However, there is no wide literature which considers supplier selection when there is large number of potential suppliers.

Techniques of artificial intelligence such as backpropagation networks, support vector machines, and $k$-nearest neighbors may be used for $\mathrm{ABC}$ inventory classification, taking into account several criteria [19]. Also, ABC classification may be supported by using different methods such as Analytic Hierarchy Process and Data Envelopment Analysis [20]. In some cases, existing models may be analysed and improved, such as extension of the $\mathrm{Ng}$-model for multicriteria inventory ABC classification [20]. In this way, classification may be performed by respect to multicriteria and their weights, simultaneously. The criteria weights may be obtained by using DEA [20]. If criteria are uncertain, such as the fact that demand frequency and costs are in focus, fuzzy ABC model for classification of items according to their value may be applied [21]. As the values of classification criteria are uncertain, they may be described by triangular fuzzy numbers [15] and may be aggregated into one by multiplying two corresponding criteria values. In this way, 
value of aggregated classification criteria is described by fuzzy number which may be defuzzified and classification may be performed by application of conventional ABC. In a case of existing variables with either nominal or nonnominal values and incorporated management experience and judgment, a fuzzy rule based approach to $\mathrm{ABC}$ classification may be applied [22].

The values of the treated classification items should be ranked according to the value of classification criterion in monotonically decreasing string. Typically, items of class A represent about $5-10 \%$ of the total number of items; approximately next $15 \%$ of items correspond to the group $\mathrm{B}$ and the rest of the items belong to the group $\mathrm{C}$. The items of class $\mathrm{A}$ are the most significant in the treated issue respecting the classification criteria. In treated problem of suppliers' selection, ABC method may be deployed for determining optimal portfolio of suppliers (classified A group of suppliers). Optimal portfolio of suppliers should be ranked in order to propose optimal purchasing strategy through building potential partnership with the best ranked suppliers. Optimal portfolio of suppliers may be ranked by applying different supplier selection models [23]. Amongst many methodologies, ELECTRE may be seen as a proven asset for multicriteria decision analysis finding applications in wide scientific fields [24]. When the issue of supplier selection is in focus, the determination of preference of alternatives may be set as a group decision making problem [25]. ELECTRE method may be used for dealing with multicriteria decision problems such as determination of master contractor when there are several subcontractors [26]. In this case, index of preference is modified and it is calculated as a product of fuzzy triangular numbers. ELECTRE may be modified in way that the value of criteria for each supplier may be assessed by three decision makers whose assessments are modelled by fuzzy numbers [27]. In this proposed fuzzy ELECTRE, Hamming distance is used for comparing the suppliers on the treated criteria.

In compliance with the results of good practice, it may be noticed that the evaluation criteria used for the supplier selection often do not have the same relative importance. The relative importance does not depend on supplier and it is not subordinated to change over time. Usually decision makers deliver better opinions by using linguistic expressions than precise numbers. It may be suggested that it is closer to human thinking to compare relative importance of each pair of criteria than to perform direct assessment. Respecting these facts, many authors determine relative importance through the fuzzy AHP framework [28]. Handling of uncertainties may be performed by using extent analysis [29].

\section{Evaluation Framework and Modelling of Uncertainties}

Step 1. Potential suppliers may be formally presented as a set of indices $\iota=\{1, \ldots, i, \ldots, I\}$ where $I$ is the total number of suppliers and $i$ is the index of the possible supplier. In this case, a set of suppliers is defined according to results of good practice.
Step 2. Evaluation criteria are presented by set of indices $\kappa=$ $\{1, \ldots, k, \ldots, K\}$, where $K$ is the total number of criteria and $k$ is index of criterion. The number and type of criteria are defined by the management team based on the experience, the results of benchmarking, and current information about suppliers which are presented in reports.

Step 3. Management team of the enterprise is formally presented by set of indices $\varepsilon=\{1, \ldots, e, \ldots, E\}$, where $E$ is the total number of the decision makers and $e$ is the index of decision maker. In the considered problem, the management team of treated enterprise which exists within the global supply chain consisted of purchasing manager, main manager, plant manager, and financial manager. It may be assumed that the decision makers have different importance for evaluation and selection of suppliers' problem. The decision maker's weight is denoted as $\omega_{e}, e=1, \ldots, E$. These weights are given with respect to the results of good practice. For considered problem, the weights of decision makers are $0.3,0.3,0.2$, and 0.2 , respectively.

Step 4. The relative importance of each pair of criteria is assessed by each decision maker. The decision maker uses predefined linguistic expressions which are modelled by triangular fuzzy numbers (TFNs). The aggregated values of the fuzzy pairwise matrix of the relative importance of criteria are calculated by using Fuzzy Averaging Ordered Method (FOWA) [30]. The weights vector is given by extent analyses method [29]. The criteria weights are described by precise values.

Step 5. The possible suppliers should be evaluated according to the predefined period of time. Usually, it is a period of one year. In general, the time period is divided into small time intervals. In other words, the assessment of suppliers is performed in discreet time periods. Time period is presented by set of indices $\tau=\{1, \ldots, t, \ldots, T\}$, where $T$ is the total number of discretized intervals and $t$ is the index of time interval.

Step 6. The criterion value for supplier is assessed by each decision maker for each time period $t$. Decision makers use predefined linguistic expressions which are modelled by TFNs. The aggregated values of criteria values for suppliers over time period are given by using fuzzy averaging method.

Step 7. The crisp values of decision matrix are given by applying moment method [15].

Step 8. Classification of possible suppliers with respect to all criteria and their weights is performed by the proposed $\mathrm{ABC}$ model.

Step 9. Fuzzy decision matrix of suppliers which belong to group A is stated. The rank of these suppliers is determined by fuzzy ELECTRE method.

3.1. Modelling of Uncertainties. Rating of the relative importance of evaluation criteria and their values are based on 
uncertain and imprecise knowledge of decision makers. Modelling of these uncertainties is based on fuzzy set theory $[13,15]$ which is a suitable mathematical tool for presenting uncertain numbers in quantitative way. Fuzzy set is defined by its membership function which can be obtained in different ways [14]. The uncertainties which exist in real problems are often modelled by TFNs because they offer a good compromise between descriptive power and computational simplicity. The number of TFNs assigned to the uncertainties into the relative importance of criteria and criteria values is defined by management team of global supply chain. The domain of defined TFNs is defined on the real line which belong to different intervals. In the literature, there are no rules or suggestions on how to determine the domain and granularity of fuzzy numbers.

3.1.1. Modelling of Criteria Relative Importance. The relative importance of evaluation criteria is unchangeable during the considered period of time. The assessment of relative importance of each pair of identified criteria is performed by each decision maker. They use predefined linguistic expressions which are modelled by TFNs, $\widetilde{W}_{k k^{\prime}}^{e}=\left(x ; l_{k k^{\prime}}^{e}, m_{k k^{\prime}}^{e}, u_{k k^{\prime}}^{e}\right)$, which are defined in the following way:

$$
\begin{aligned}
& \text { Low importance }(\mathrm{L}):(x ; 1,1,5) \\
& \text { Medium importance }(\mathrm{M}):(x ; 1,3,5) \\
& \text { High importance }(\mathrm{H}):(x ; 1,5,5) .
\end{aligned}
$$

The domains of these TFNs are defined real line into interval $[1,5]$. The value 1 denotes that criterion $k$ over criterion $k^{\prime}$ has equal importance. Value 5 means that the relative importance of criterion $k$ over criterion $k^{\prime}$ has the most importance.

If the strong relative importance of criterion $k^{\prime}$ over criterion $k$ holds, then the pairwise comparison scale can be represented by the fuzzy number $\widetilde{W}_{k k^{\prime}}^{e}=\left(\widetilde{W}_{k^{\prime} k}^{e}\right)^{-1}=$ $\left(1 / u_{k^{\prime} k^{\prime}}^{e}, 1 / m_{k^{\prime} k^{\prime}}^{e}, 1 / l_{k^{\prime} k}^{e}\right)$.

3.2. Modelling of Criteria Values. In the practice, uncertain criteria values are assessed by management team at the global supply chain level for each time interval. Their judgments are based on evidence data, results of good practice, experience, and so forth. It could be assumed that management team makes decision by consensus. In this paper, fuzzy rating of uncertain criteria values at the time interval level is described by linguistic expressions which can be represented as TFNs $\widetilde{v}_{i k}^{t}=\left(y ; L_{i k}^{t}, M_{i k}^{t}, U_{i k}^{t}\right)$. Values in the domain of these TFNs are defined on measurement scale which belong to areal set within the interval $[0,1]$. Value 0 and 1 denote that criterion $k$ for each supplier at the time interval level is at the lowest value and the highest value, respectively.

Specifically, seven linguistic expressions, which are modelled by TFNs, are used:

$$
\begin{aligned}
& \text { Very low: }(y ; 0,0,0.25) \\
& \text { Low: }(y ; 0.1,0.2,0.3)
\end{aligned}
$$

Fairly medium moderate: $(y ; 0.15,0.3,0.45)$

Moderate: $(y ; 0.35,0.5,0.65)$
Fairly high: $(y ; 0.55,0.7,0.85)$

High: $(y ; 0.7,0.8,0.9)$

Very high: $(y ; 0.75,1,1)$.

\section{The Proposed Algorithm}

The algorithm of the proposed model is presented as follows.

Step 1. Fuzzy assessment of the relative importance of each criteria pair is presented in matrix form:

$$
\left[\widetilde{W}_{k k^{\prime}}^{e}\right]_{K \times K}
$$

Step 2. The aggregated value of each pair of criteria is calculated:

$$
\widetilde{W}_{k k^{\prime}}=\sum_{e=1}^{E} \omega_{e} \cdot \widetilde{W}_{k k^{\prime}}^{e}
$$

The fuzzy pairwise comparison matrix of the relative importance of criteria is constructed:

$$
\left[\widetilde{W}_{k k^{\prime}}\right]_{K \times K}
$$

The weights vector is determined by using the concept of extent analysis [29] which is presented in the following manner. The value of fuzzy synthetic extent $S_{k}$, with respect to the $k$ th criterion, is defined as follows:

$$
\begin{aligned}
\widetilde{S}_{k}= & \left(\sum_{k^{\prime}=1}^{K} l_{k k^{\prime}}, \sum_{k^{\prime}=1}^{K} m_{k k^{\prime}}, \sum_{k^{\prime}=1}^{K} l_{k k^{\prime}}\right) \\
& \cdot\left(\sum_{k=1}^{K} \sum_{k^{\prime}=1}^{K} l_{k k^{\prime}}, \sum_{k=1}^{K} \sum_{k^{\prime}=1}^{K} m_{k k^{\prime}}, \sum_{k=1}^{K} \sum_{k^{\prime}=1}^{K} u_{k k^{\prime}}\right) .
\end{aligned}
$$

The weights vector is represented as follows:

$$
W_{p}=\left(\left(\operatorname{Bel}\left(\widetilde{S}_{1}\right)\right), \ldots,\left(\operatorname{Bel}\left(\widetilde{S}_{k}\right)\right), \ldots,\left(\operatorname{Bel}\left(\widetilde{S}_{K}\right)\right)\right) .
$$

The measure of belief according to which TFN, $\widetilde{S}_{k}$, is bigger than all other TFNs $\widetilde{S}_{k^{\prime}}$, is denoted as $\operatorname{Bel}\left(\widetilde{S}_{k}\right)$. This value is obtained by applying the method for fuzzy numbers comparison [31, 32]. These values are crisp.

The normalized weights vector is given by using linear normalization procedure for benefit type criteria [33].

Step 3. The fuzzy rating of criterion $k$, for each supplier at the time interval level $t$, is performed by each decision maker. These values are presented by TFNs, $\widetilde{v}_{i k}^{t}$.

Step 4. The value of criterion $k$ for each supplier for the whole time period, $\widetilde{v}_{i k}$, is obtained by using the fuzzy averaging method:

$$
\widetilde{v}_{i k}=\frac{1}{T} \cdot \sum_{t=1}^{T} \widetilde{v}_{i k}^{t}
$$


Step 5. The weighted fuzzy criterion value, $\widetilde{r}_{i k}$, is calculated as follows:

$$
\widetilde{r}_{i k}=w_{k} \cdot \widetilde{v}_{i k}
$$

Step 6. The class A of items is determined as follows.

Class A contains suppliers that have high rated criteria customer care, quality, and delivery method. The highest values of identified criteria are represented by crisp values, $w_{1}, w_{2}, w_{3}$, respectively. According to fuzzy algebra rules, these crisp values should be represented by TFNs: $\left(w_{1}, 1\right)$, $\left(w_{2}, 1\right)$, and $\left(w_{3}, 1\right)$, respectively. In order to determine whether a supplier belongs to class A, the Euclidian distance of supplier $i, i=1, \ldots, I$, represented by $\left(\widetilde{r}_{i 1}, \widetilde{r}_{i 2}, \widetilde{r}_{i 3}\right)$, from the highest criteria values is calculated as follows:

$$
\operatorname{dist}(i, \operatorname{ref} A)=\operatorname{defuzz}\left\{\sqrt{\sum_{k=1}^{3}\left(w_{k}-\tilde{r}_{i k}\right)^{2}}\right\} \text {. }
$$

As $\widetilde{r}_{i k}$ are fuzzy numbers, their distance to $\operatorname{ref} A$ is also a fuzzy number. The supports of fuzzy numbers $\operatorname{dist}(i, \operatorname{ref} A)$ can be described in discrete forms by discrete with membership degree $\min _{k=1, \ldots, K}\left(\mu_{\widetilde{r}_{i k}}(y)\right)$.

Once, the distances of all possible suppliers from $\operatorname{ref} A$ are calculated, they are ranked in the ascending order. The first 5$10 \%$ of the corresponding ranked suppliers are classified into class A.

Step 7. The class $\mathrm{C}$ of items is determined as follows.

Suppliers that have low criteria values belong to class C. The reference point ref $C$ is defined as the arranged triplet crisp values $(0,0,0)$, for care about clients, quality, and delivery method.

The weighted refC is also represented as arranged triplet $(0,0,0)$. Similarly, as in the previous step, a fuzzy distance between supplier $i, i=1, \ldots, I$, and weighted $\operatorname{ref} C$ is calculated as follows:

$$
\operatorname{dist}(i, \operatorname{ref} C)=\operatorname{defuzz}\left\{\sqrt{\sum_{k=1}^{3}\left(0-\tilde{r}_{i k}\right)^{2}}\right\} \text {. }
$$

The distances have to be ranked in the ascending order. The first $80 \%$ distances correspond to suppliers which belong to class C.

Step 8. Suppliers that are not classified either into class A or into class $\mathrm{C}$ form class $\mathrm{B}$.

Step 9. The weighted decision matrix for suppliers from class of $\mathrm{A}$ is constructed.

Step 10. The sets of concordance $S_{i i^{\prime}}$, and the sets of discordance $N S_{i i^{\prime}}$, are determined in the following way. If $\widetilde{r}_{i^{\prime} k} \geq$ $\tilde{r}_{i k},\left(i, i^{\prime}=1, \ldots, I_{1}\right)$ then criteria $k$ belongs to the set of concordance. The total number of suppliers of class $\mathrm{A}$ is denoted as $I_{1}, I_{1} \leq I$. If $\tilde{r}_{i^{\prime} k}<\widetilde{r}_{i k}\left(i, i^{\prime}=1, \ldots, I_{1}\right)$ then criterion $k$ belongs to the set of disordinance. The fuzzy numbers, $\widetilde{r}_{i^{\prime} k}, \widetilde{r}_{i k}$, are compared by using method which is developed in $[31,32]$.
Step 11. Construction of concordance matrix, $C=\left[c_{i i^{\prime}}\right]_{I \times I}$, and discordance matrix, $N=\left[n_{i i^{\prime}}\right]_{I \times I}$, is performed, where

$$
\begin{gathered}
c_{i i^{\prime}}= \begin{cases}0 & \tilde{r}_{i^{\prime} k}<\widetilde{r}_{i k} \text { if } S_{i i^{\prime}}=\{0\} \\
\sum_{k \in S_{i i^{\prime}}} w_{k} \quad \tilde{r}_{i^{\prime} k} \geq \tilde{r}_{i k} \text { if } S_{i i^{\prime}} \neq\{0\}\end{cases} \\
n_{i i^{\prime}}= \begin{cases}0 & \tilde{r}_{i^{\prime} k}>\widetilde{r}_{i k} \\
\frac{\max _{k \in N S_{i i^{\prime}}}\left(d\left(\widetilde{r}_{i^{\prime} k}, \widetilde{r}_{i k}\right)\right)}{\max _{k=1, \ldots, K} d\left(\tilde{r}_{i^{\prime} k}, \tilde{r}_{i k}\right)} & \text { otherwise, }\end{cases}
\end{gathered}
$$

where $d\left(\widetilde{r}_{i k}, \widetilde{r}_{i^{\prime} k}\right)$ is distance between two fuzzy numbers which is obtained by applying vertex method [34]:

$$
\begin{aligned}
& d\left(\tilde{r}_{i k}, \tilde{r}_{i^{\prime} k}\right) \\
& \quad=\sqrt{\frac{1}{3} \cdot\left[\left(l_{i k}-l_{i^{\prime} k}\right)^{2}+\left(m_{i k}-m_{i^{\prime} k}\right)^{2}+\left(u_{i k}-u_{i^{\prime} k}\right)^{2}\right]} .
\end{aligned}
$$

Mean value of concordance coefficient $c_{s r}$, and coefficient of discordance, $n_{s r}$, is obtained according to the following expressions:

$$
\begin{aligned}
& c_{s r}=\frac{1}{I \cdot(I-1)} \sum_{i=1}^{I} \sum_{i=1}^{I} c_{i i^{\prime}}, \\
& n_{s r}=\frac{1}{I \cdot(I-1)} \sum_{i=1}^{I} \sum_{i=1}^{I} n_{i i^{\prime}} .
\end{aligned}
$$

Step 12. The concordance matrix should be generated, $M=$ $\left[m_{i i^{\prime}}\right]_{I \times I}$. Elements of this matrix are determined by the following rules:

(i) Elements on the main diagonal are not defined.

(ii) $m_{i i^{\prime}}=0$ for those pair of alternatives $\left(i, i^{\prime}\right)$, where $c_{i i^{\prime}}<$ $c_{s r} \vee n_{i i^{\prime}}>n_{s r}$.

(iii) $m_{i i^{\prime}}=1$ for those pair of alternatives $\left(i, i^{\prime}\right)$, where $c_{i i^{\prime}} \geq$ $c_{s r} \wedge n_{i i^{\prime}} \leq n_{s r}$.

Step 13. Rank of suppliers of group A with respect to all criteria and their weights is determined according to the concordance matrix. The best supplier is one with greatest number in the concordance matrix.

\section{Illustrative Example}

Illustrative example is presented as a verification for the proposed model. The large group of potential suppliers is analysed for the ABC classification since all of suppliers could deliver needed products and they are geographically distributed all over the world. It is worth to mention that analysed enterprise is performing suppliers' selection in building and civil engineering industry. 
Fuzzy assessment according to the Step 1 should be performed:

$$
\left[\begin{array}{cc}
1,1,1,1 \frac{1}{M}, \frac{1}{H}, \frac{1}{M}, \frac{1}{L} & \frac{1}{L}, \frac{1}{M}, \frac{1}{M}, \frac{1}{H} \\
1,1,1,1 & 1, M, 1, L \\
1,1,1,1
\end{array}\right] .
$$

Aggregated values of judgements of decision makers are obtained by FOWA. This procedure is presented on criteria 2 and 3 (Step 2):

$$
\begin{aligned}
\widetilde{W}_{23}= & \sum_{e=1}^{4} \omega_{e} \cdot \widetilde{W}_{k k^{\prime}}^{e} \\
= & 0.3 \cdot(1,1,1)+0.3 \cdot(1,3,5)+0.2 \cdot(1,1,1) \\
& +0.2 \cdot(1,1,5)=(1,1.6,3) .
\end{aligned}
$$

Fuzzy pairwise comparison matrix of the aggregated relative importance of criteria is

$$
\left[\begin{array}{ccc}
(1,1,1) & (0.15,0.425,1) & (0.2,0.505,1) \\
(1,2.35,6.667) & (1,1,1) & (1,1.6,3) \\
(1,1.980,5) & (0.333,0.625,1) & (1,1,1)
\end{array}\right]
$$

By applying the procedure developed by Chang [29], the normalized weights vector is $W=(0.22,0.47,0.31)$.

By applying the proposed algorithm (Steps 3-5), the results are obtained and presented in Table 1.

According to Step 6 of the proposed algorithm the rank of suppliers is obtained and presented in Table 2.

Ranked suppliers classified into class A are $(i=2),(i=1)$, $(i=41)$, and $(i=36)$.

According to Step 7 of the proposed algorithm the rank of suppliers is obtained and presented in Table 3.

Ranked suppliers are classified into class $\mathrm{C}$ are $(i=27)$, (i=26), $(i=40),(i=34),(i=18),(i=39),(i=17),(i=21)$, (i=25), $(i=38),(i=15),(i=16),(i=14),(i=20),(i=31)$, $(i=37),(i=42),(i=11),(i=19),(i=22),(i=10),(i=23)$, $(i=30),(i=28),(i=29),(i=6),(i=4),(i=8),(i=24)$, $(i=12),(i=7),(i=13)$, and $(i=3)$.

The rest of suppliers belong to class B (Step 8 of the proposed algorithm). These suppliers are $(i=5),(i=9)$, $(i=32)$, and $(i=25)$.

The fuzzy weighted decision matrix is constructed (Step 10 of the proposed algorithm) and presented in Table 4.

The sets of concordance and sets of discordance are (Step 10 of the proposed algorithm):

$$
\begin{aligned}
S_{2,1} & =\left\{k_{1}, k_{2}\right\}, \\
N S_{2,1} & =\left\{k_{3}\right\}, \\
S_{2,41} & =\left\{k_{2}\right\}, \\
N S_{2,41} & =\left\{k_{1}, k_{3}\right\}, \\
S_{2,36} & =\left\{k_{2}\right\}, \\
N S_{2,36} & =\left\{k_{1}, k_{3}\right\},
\end{aligned}
$$

$$
\begin{aligned}
S_{1,2} & =\left\{k_{3}\right\}, \\
N S_{2,1} & =\left\{k_{1}, k_{2}\right\}, \\
S_{1,41} & =\left\{k_{2}\right\}, \\
N S_{1,41} & =\left\{k_{1}, k_{3}\right\}, \\
S_{1,36} & =\left\{k_{2}\right\}, \\
N S_{1,36} & =\left\{k_{1}, k_{3}\right\}, \\
S_{41,2} & =\left\{k_{1}, k_{3}\right\}, \\
N S_{41,2} & =\left\{k_{2}\right\}, \\
S_{41,1} & =\left\{k_{1}, k_{3}\right\}, \\
N S_{41,1} & =\left\{k_{2}\right\}, \\
S_{41,36} & =\left\{k_{2}\right\}, \\
N S_{41,36} & =\left\{k_{1}, k_{3}\right\}, \\
S_{36,2} & =\left\{k_{1}, k_{3}\right\}, \\
N S_{36,2} & =\left\{k_{2}\right\}, \\
S_{36,1} & =\left\{k_{1}, k_{3}\right\}, \\
N S_{36,41} & =\left\{k_{2}\right\}, \\
\left.N k_{1}, k_{3}\right\}, & =\left\{k_{2}\right\} . \\
N &
\end{aligned}
$$

According to Step 11 of the proposed algorithm, the matrix of concordance and the matrix of discordance may be presented in the following way:

$$
C=\left[\begin{array}{cccc}
- & 0.69 & 0.47 & 0.47 \\
0.31 & - & 0.47 & 0.47 \\
0.53 & 0.53 & - & 0.47 \\
0.53 & 0.53 & 0.53 & -
\end{array}\right]
$$

Distance between TFNs (see (12)) $\tilde{r}_{2 k}, \tilde{r}_{41 k}, k=1,2,3$, are

$$
\begin{aligned}
& d\left(\widetilde{r}_{21}, \widetilde{r}_{41,1}\right) \\
& =\sqrt{\frac{1}{3} \cdot\left[(0.151-0.118)^{2}+(0.192-0.148)^{2}+(0.201-0.179)^{2}\right]} \\
& =0.0342, \\
& d\left(\widetilde{r}_{22}, \widetilde{r}_{41,2}\right) \\
& =\sqrt{\frac{1}{3} \cdot\left[(0.294-0.30)^{2}+(0.352-0.376)^{2}+(0.411-0.423)^{2}\right]} \\
& =0.0159,
\end{aligned}
$$


TABLE 1: The weighted aggregated criteria values.

\begin{tabular}{|c|c|c|c|c|c|}
\hline Country & Supplier & Seaport & $k=1$ & $k=2$ & $k=3$ \\
\hline Brazil & $i=1$ & Vitoria & $(0.162,0.209,0.214)$ & $(0.294,0.352,411)$ & $(0.182,0.232,0.263)$ \\
\hline Brazil & $i=2$ & Vitoria & $(0.151,0.192,0.201)$ & $(0.294,0.352,0.411)$ & $(0.209,0.256,0.283)$ \\
\hline Brazil & $i=3$ & Vitoria & $(0.154,0.204,0.212)$ & $(0.276,0.341,0.406)$ & $(0.109,0.155,0.202)$ \\
\hline Brazil & $i=4$ & Vitoria & $(0.151,0.192,0.206)$ & $(0.270,0.329,0.388)$ & $(0.073,0.116,0.159)$ \\
\hline Brazil & $i=5$ & Vitoria & $(0.154,0.204,0.212)$ & $(0.346,0.447,0.458)$ & $(0.089,0.132,0.174)$ \\
\hline Brazil & $i=6$ & Vitoria & $(0.151,0.193,0.207)$ & $(0.253,0.317,0.382)$ & $(0.089,0.132,0.175)$ \\
\hline Brazil & $i=7$ & Vitoria & $(0.160,0.20,0.209)$ & $(0.294,0.364,0.406)$ & $(0.051,0.085,0.116)$ \\
\hline Brazil & $i=8$ & Saupe & $(0.066,0.099,0.132)$ & $(0.294,0.352,0.411)$ & $(0.139,0.186,0.232)$ \\
\hline Brazil & $i=9$ & Vitoria & $(0.162,0.209,0.215)$ & $(0.311,0.364,0.417)$ & $(0.078,0.124,0.171)$ \\
\hline Brazil & $i=10$ & Vitoria & $(0.160,0.198,0.209)$ & $(0.164,0.235,0.306)$ & $(0.139,0.186,0.232)$ \\
\hline Brazil & $i=11$ & Vitoria & $(0.162,0.209,0.215)$ & $(0.117,0.188,0.258)$ & $(0.167,0.209,0.252)$ \\
\hline Brazil & $i=12$ & Vitoria & $(0.151,0.192,0.206)$ & $(0.341,0.352,0.411)$ & $(0.078,0.124,0.171)$ \\
\hline Brazil & $i=13$ & Vitoria & $(0.129,0.195,0.190)$ & $(0.311,0.364,0.417)$ & $(0.078,0.124,0.171)$ \\
\hline Brazil & $i=14$ & Vitoria & $(0.110,0.143,0.176)$ & $(0.111,0.188,0.259)$ & $(0.139,0.171,0.194)$ \\
\hline Brazil & $i=15$ & Santos & $(0.063,0.094,0.124)$ & $(0.182,0.115,0.146)$ & $(0.050,0.085,0.139)$ \\
\hline Brazil & $i=16$ & Vitoria & $(0.110,0.143,0.176)$ & $(0.159,0.223,0.288)$ & $(0.054,0.093,0.132)$ \\
\hline Brazil & $i=17$ & Vitoria & $(0.063,0.094,0.124)$ & $(0.094,0.164,0.235)$ & $(0.101,0.139,0.178)$ \\
\hline Brazil & $i=18$ & Saupe & $(0.066,0.099,0.132)$ & $(0.118,0.188,0.258)$ & $(0.027,0.054,0.101)$ \\
\hline Brazil & $i=19$ & Vitoria & $(0.099,0.132,0.165)$ & $(0.235,0.317,0.370)$ & $(0.066,0.101,0.155)$ \\
\hline Brazil & $i=20$ & Saupe & $(0.041,0.072,0.102)$ & $(0.205,0.270,0.335)$ & $(0.031,0.062,0.112)$ \\
\hline China & $i=21$ & Xiamen & $(0.118,0.154,0.176)$ & $(0.053,0.106,0.188)$ & $(0.140,0.171,0.221)$ \\
\hline India & $i=22$ & Chennai & $(0.129,0.165,0.187)$ & $(0.229,0.294,0.358)$ & $(0.089,0.132,0.174)$ \\
\hline India & $i=23$ & Chennai & $(0.126,0.165,0.176)$ & $(0.247,0.305,0.364)$ & $(0.089,0.132,0.174)$ \\
\hline India & $i=24$ & Mumbai & $(0.129,0.165,0.187)$ & $(0.30,0.376,0.423)$ & $(0.031,0.062,0.113)$ \\
\hline India & $i=25$ & Chennai & $(0.129,0.165,0.187)$ & $(0.317,0.388,0.429)$ & $(0.074,0.116,0.159)$ \\
\hline India & $i=26$ & Mumbai & $(0.041,0.072,0.102)$ & $(0.071,0.117,0.194)$ & $(0.078,0.109,0.159)$ \\
\hline India & $i=27$ & Chennai & $(0.019,0.038,0.072)$ & $(0.035,0.070,0.135)$ & $(0.054,0.093,0.132)$ \\
\hline Italy & $i=28$ & Carrara & $(0.118,0.148,0.179)$ & $(0.253,0.317,0.382)$ & $(0.093,0.139,0.186)$ \\
\hline Italy & $i=29$ & Carrara & $(0.052,0.082,0.113)$ & $(0.235,0.388,0.429)$ & $(0.050,0.085,0.104)$ \\
\hline Italy & $i=30$ & Verona & $(0.096,0.126,0.157)$ & $(0.235,0.306,0.376)$ & $(0.132,0.171,0.209)$ \\
\hline Italy & $i=31$ & Carrara & $(0.140,0.176,0.198)$ & $(0.229,0.294,0.358)$ & $(0.132,0.170,0.209)$ \\
\hline Italy & $i=32$ & Carrara & $(0.074,0.104,0.135)$ & $(0.305,0.40,0.435)$ & $(0.151,0.201,0.232)$ \\
\hline Italy & $i=33$ & Verona & $(0.074,0.104,0.135)$ & $(0.141,0.211,0.282)$ & $(0.046,0.077,0.128)$ \\
\hline Italy & $i=34$ & Verona & $(0.071,0.099,0.126)$ & $(0.088,0.153,0.217)$ & $(0.062,0.093,0.143)$ \\
\hline Portugal & $i=35$ & Lisboa & $(0.060,0.066,0.115)$ & $(0.165,0.235,0.306)$ & $(0.050,0.085,0.140)$ \\
\hline Singapore & $i=36$ & Singapore & $(0.085,0.116,0.146)$ & $(0.322,0.411,0.440)$ & $(0.163,0.202,0.240)$ \\
\hline Spain & $i=37$ & Vigo & $(0.079,0.104,0.115)$ & $(0.223,0.282,0.341)$ & $(0.116,0.155,0.194)$ \\
\hline Spain & $i=38$ & Porbido & $(0.601,0.088,0.115)$ & $(0.182,0.247,0.288)$ & $(0.035,0.070,0.105)$ \\
\hline Spain & $i=39$ & Novelda & $(0.074,0.104,0.135)$ & $(0,088,0.153,0.217)$ & $(0.120,0.163,0.205)$ \\
\hline Spain & $i=40$ & Valencia & $(0.066,0.099,0.132)$ & $(0.065,0.129,0.091)$ & $(0.054,0.078,0.14)$ \\
\hline Taiwan & $i=41$ & Keelung & $(0.118,0.148,0.179)$ & $(0.30,0.376,0.423)$ & $(0.163,0.209,0.236)$ \\
\hline Taiwan & $i=42$ & Keelung & $(0.069,0.094,0.118)$ & $(0.229,0.294,0.358)$ & $(0.097,0.140,0.182)$ \\
\hline
\end{tabular}

$d\left(\widetilde{r}_{23}, \widetilde{r}_{41,3}\right)$

$=\sqrt{\frac{1}{3} \cdot\left[(0.209-0.163)^{2}+(0.256-0.209)^{2}+(0.283-0.236)^{2}\right]}$

$=0.0467$.
The value of discordance matrix element (see (11)) is

$$
n_{2,41} \frac{\max _{k=1,3}(0.0342,0.0467)}{\max _{k=1,2,3}(0.0342,0.0159,0.0467)}=\frac{0.0467}{0.0467}
$$

(19)

$$
=1 \text {. }
$$


TABle 2: Rank suppliers from refA.

\begin{tabular}{|c|c|c|c|}
\hline Supplier & $\operatorname{dist}(i, \operatorname{ref} A)=\operatorname{defuzz}\left\{\sqrt{\sum_{k=1}^{3}\left(w_{k}-\tilde{r}_{i k}\right)^{2}}\right\}$ & Supplier & $\operatorname{dist}(i, \operatorname{ref} A)=\operatorname{defuzz}\left\{\sqrt{\sum_{k=1}^{3}\left(w_{k}-\tilde{r}_{i k}\right)^{2}}\right.$ \\
\hline$i=2$ & 0.1354 & $i=42$ & 0.2716 \\
\hline$i=1$ & 0.144 & $i=19$ & 0.2737 \\
\hline$i=41$ & 0.1594 & $i=29$ & 0.2864 \\
\hline$i=36$ & 0.1655 & $i=11$ & 0.2867 \\
\hline$i=32$ & 0.1785 & $i=31$ & 0.3129 \\
\hline$i=5$ & 0.1824 & $i=14$ & 0.3265 \\
\hline$i=3$ & 0.2027 & $i=15$ & 0.3376 \\
\hline$i=8$ & 0.2096 & $i=16$ & 0.3378 \\
\hline$i=9$ & 0.2147 & $i=20$ & 0.3503 \\
\hline$i=25$ & 0.2197 & $i=38$ & 0.3532 \\
\hline$i=12$ & 0.2224 & $i=35$ & 0.3581 \\
\hline$i=13$ & 0.2291 & $i=33$ & 0.366 \\
\hline$i=6$ & 0.2351 & $i=39$ & 0.3682 \\
\hline$i=30$ & 0.2352 & $i=17$ & 0.3712 \\
\hline$i=28$ & 0.2405 & $i=27$ & 0.3904 \\
\hline$i=4$ & 0.2418 & $i=21$ & 0.3908 \\
\hline$i=7$ & 0.2494 & $i=18$ & 0.3983 \\
\hline$i=23$ & 0.2498 & $i=34$ & 0.4017 \\
\hline$i=22$ & 0.2567 & $i=40$ & 0.4271 \\
\hline$i=10$ & 0.2598 & $i=26$ & 0.4285 \\
\hline$i=37$ & 0.2699 & & \\
\hline$i=24$ & 0.2699 & & \\
\hline
\end{tabular}

TABLE 3: Rank suppliers from refC.

\begin{tabular}{|c|c|c|c|}
\hline Supplier & $\operatorname{dist}(i, \operatorname{ref} C)=\operatorname{defuzz}\left\{\sqrt{\sum_{k=1}^{3}\left(0-\widetilde{r}_{i k}\right)^{2}}\right\}$ & Supplier & $\operatorname{dist}(i, \operatorname{ref} C)=\operatorname{defuzz}\left\{\sqrt{\sum_{k=1}^{3}\left(0-\widetilde{r}_{i k}\right)^{2}}\right.$ \\
\hline$i=27$ & 0.1254 & $i=19$ & 0.3558 \\
\hline$i=26$ & 0.1789 & $i=22$ & 0.3611 \\
\hline$i=40$ & 0.1826 & $i=10$ & 0.3661 \\
\hline$i=34$ & 0.2055 & $i=23$ & 0.3693 \\
\hline$i=18$ & 0.2197 & $i=30$ & 0.3720 \\
\hline$i=39$ & 0.2231 & $i=28$ & 0.3764 \\
\hline$i=17$ & 0.2349 & $i=29$ & 0.3813 \\
\hline$i=33$ & 0.2481 & $i=6$ & 0.3931 \\
\hline$i=21$ & 0.2559 & $i=4$ & 0.3968 \\
\hline$i=35$ & 0.2595 & $i=8$ & 0.4111 \\
\hline$i=38$ & 0.2714 & $i=24$ & 0.4113 \\
\hline$i=15$ & 0.2792 & $i=12$ & 0.4178 \\
\hline$i=16$ & 0.2840 & $i=7$ & 0.4199 \\
\hline$i=14$ & 0.2864 & $i=13$ & 0.4202 \\
\hline$i=20$ & 0.2864 & $i=3$ & 0.4242 \\
\hline$i=31$ & 0.3111 & $i=25$ & 0.4330 \\
\hline$i=37$ & 0.3382 & $i=9$ & 0.4353 \\
\hline$i=42$ & 0.3414 & $i=32$ & 0.4518 \\
\hline$i=11$ & 0.3481 & $i=5$ & 0.4971 \\
\hline
\end{tabular}


TABLE 4: The weighted decision matrix.

\begin{tabular}{lccr}
\hline & $k=1$ & $k=2$ & $k=3$ \\
\hline$i=2$ & $(0.151,0.192,0.201)$ & $(0.294,0.352,0.411)$ & $(0.209,0.256,0.283)$ \\
$i=1$ & $(0.162,0.209,0.214)$ & $(0.276,0.352,0.411)$ & $(0.182,0.232,0.263)$ \\
$i=41$ & $(0.118,0.148,0.179)$ & $(0.30,0.376,0.423)$ & $(0.163,0.209,0.236)$ \\
$i=36$ & $(0.085,0.116,0.146)$ & $(0.322,0.411,0.440)$ & $(0.163,0.202,0.240)$ \\
\hline
\end{tabular}

TABLE 5: Rank of suppliers of group A.

\begin{tabular}{lc}
\hline & Rank \\
\hline$i=2$ & 4 \\
$i=1$ & 3 \\
$i=41$ & $1-2$ \\
$i=36$ & $1-2$ \\
\hline
\end{tabular}

The values of discordance matrix are calculated in same way. The matrix of discordance is as follows:

$$
N=\left[\begin{array}{cccc}
- & 1 & 1 & 1 \\
0.583 & - & 0.759 & 1 \\
0.340 & 0.433 & - & 1 \\
0.623 & 0.579 & 0.790 & -
\end{array}\right] .
$$

The mean value of concordance coefficient $c_{s r}$ and coefficient of disconcordance $n_{s r}$ are calculated in the following way (see (13)):

$$
\begin{aligned}
& c_{s r}=\frac{1}{4 \cdot(4-1)} \sum_{i=1}^{4} \sum_{i=1}^{4} c_{i i^{\prime}}=\frac{1}{12} \cdot 6=0.5 \\
& n_{s r}=\frac{1}{4 \cdot(4-1)} \sum_{i=1}^{I} \sum_{i=1}^{I} n_{i i^{\prime}}=\frac{1}{12} \cdot 9.107=0.759 .
\end{aligned}
$$

The matrix of consistent domination is obtained according to Step 12 of the proposed algorithm, such as

$$
M=\left[\begin{array}{cccc}
- & 0 & 0 & 0 \\
0 & - & 1 & 0 \\
1 & 1 & - & 0 \\
1 & 1 & 0 & -
\end{array}\right] .
$$

The rank of suppliers of group A is given by using procedure (Step 13 of the proposed algorithm). The obtained rank is presented in Table 5.

5.1. Discussion. There are no specific guidelines for determining the classification criteria in suppliers' selection problem so these criteria vary in different economy branches. In this paper, three eliminatory criteria are chosen based on the results of good practice in order to make a base of potential suppliers. The analysed criteria are (1) customer care, (2) quality (ratio between price and specific performances of products), and (3) delivery method (ratio between costs and delivery rate). In global supply chains there is large number of potential suppliers so determining the optimal portfolio of suppliers is very important task since it may save time, decrease costs, and provide input for defining optimal supply strategy. Comparing this model to application of developed ABC models $[19,21]$, it may be stated that main implication of this model is using the new approach in classification to determine $\mathrm{A}$ and $\mathrm{C}$ class. The proposed model takes into account the type of criteria for suppliers selection so it may be assumed that it represents its main advantage.

Based on the obtained ranking results by applying the modified ELECTRE method (see Table 5), it may be concluded that suppliers $(i=41)$ and $(i=36)$ have the same importance for the treated enterprise as a part of global supply chain. With respect to the obtained result, the management team may define different supply strategy for short-time period (one year), such as exclusive purchasing form one of the selected suppliers. The selection of adequate purchasing strategy has a crucial influence on profit of enterprise within global supply chain, as well as on its market position.

In the same time, the obtained results present input data for development of the methodology for selecting suppliers in different environment, supply conditions, and external circumstances. This methodology should include various aspects of technical, economic, social, organizational, market-oriented, and environmental character. By using the mentioned methodology, management team can choose the best supplier that is suitable for building long-term and stable cooperation. This cooperation can potentially include providing capabilities for innovation and development, reliability in other partnerships, preparedness to share risk, and profit with the company.

The proposed model is focused on the real-world situation in domain determining short-time and long-time purchasing strategy. With regard to paper which treats the problem of supplier assessment and which can be found in the literature, this paper pioneers the application of classification for building optimal portfolio of suppliers and their ranking and selection within the supply chain management.

Research implications of this paper may be presented as a comparison with similar papers that have used ELECTRE method for solving similar problems as well as with papers that have used ABC classification. The weight of criteria and preference rating can be stated as fuzzy group decision making problems.

Aggregation of relative weights of criteria importance is performed by using FOWA operator comparing it to procedure proposed by Marbini and Tavana [27] or procedure proposed by Alencar et al., [25]. In practice, it is reasonable to expect that decision makers have different weights so FOWA operator seems to be more suitable. The time interval 
for assessment of preference rating is divided in sub-time intervals compared to other models where an assessment is performed during the whole time interval $[25,27]$. It is known that it is more precise to make assessment in shorter time interval.

\section{Conclusion}

Quick and continuous changes occurring in the business environment lead to opening issues in the organization and adaptation in different type of industries. One of the most important management tasks is determining of purchasing strategy, for the short-time and long-time period, respectively. This is because purchasing strategy has significant influence on successful establishment of global supply chain. As it is known, in the global supply chain, there are numerous potential suppliers, so that the considered problem is very complex.

The theoretical contributions of this paper are presented as follows. In the first place, conventional assessment of suppliers is performed with respect to quality and price. Sometimes, the other influencing criteria are disregarded. The evaluation criteria are selected according to the literature review which is conducted.

Secondly, it is appropriate to use linguistic terms instead of numerical values for describing uncertainties into (1) the relative importance of each pair of criteria and (2) criteria values which exist in the considered problem. Modelling of linguistic variables is based on the fuzzy set theory. Weights vector of criteria is obtained by applying extent analysis approach. The fuzzy AHP may be considered as suitable for capturing the vagueness of human thinking style, and in the same time, it may be effectively employed for solving the issue of determining criteria weights in the supplier selection problem.

The large number of potential suppliers in global supply chain enhances the complexity of the process of supplier selection. In that manner, it is necessary before delivery of the process of selection, to deliver the process of suppliers' classification. This may be denoted as the third contribution of the paper since a new fuzzy multicriteria $A B C$ classification of suppliers is proposed. The effectiveness of the proposed algorithm is tested using real-world data of 42 suppliers that operate in different geographical locations all over the world. The classification obtained using the algorithm is in good agreement with the judgment of the management team of the considered global supply chain.

The fourth contribution makes the ranking of the suppliers denoted as group A. The ranking is conducted by using the fuzzy ELECTRE proposed in this paper. Modification of ELECTRE may be presented as (1) determination of sets on concordance and sets of discordance [31] and (2) calculation of coefficient of discordance.

Beside abovementioned various advantages, the proposed model has some constraints. It may be seen that there is the lack of research foundation in the literature which relates to selection of criteria that are used for suppliers' selection in building and civil engineering industry. Those criteria may vary, from constrains of supplier's capacity, aggregated quality, duty taxes, and risk factors to political stability, and so forth. These extensions could undoubtedly increase the computational complexities. The second constraint relates to ABC method since it may be deployed only if $k$ is less or equal to 3. ELECTRE should be expanded with more criteria in order to determine purchasing strategy for long time and in the same time to establish partnership with supplier.

This paper focuses on the complex circumstances: a large number of suppliers from different countries, multiple decision makers involved in decision process, and multiple uncertainties. The established mathematical model can help both practitioners and researchers to further utilize and deploy the purchasing strategy in global supply chain.

\section{Competing Interests}

The authors declare that they have no competing interests.

\section{References}

[1] ISO 9001:2015 Quality management systems—Requirements.

[2] G. Bruno, E. Esposito, A. Genovese, and M. Simpson, "Applying supplier selection methodologies in a multi-stakeholder environment: a case study and a critical assessment," Expert Systems with Applications, vol. 43, pp. 271-285, 2016.

[3] A. C. Trapp and J. Sarkis, "Identifying robust portfolios of suppliers: a sustainability selection and development perspective," Journal of Cleaner Production, vol. 112, part 3, pp. 2088-2100, 2016.

[4] P. Amorim, E. Curcio, B. Almada-Lobo, A. P. Barbosa-Póvoa, and I. E. Grossmann, "Supplier selection in the processed food industry under uncertainty," European Journal of Operational Research, vol. 252, no. 3, pp. 801-814, 2016.

[5] P. H. Andersen, C. Ellegaard, and H. Kragh, "I'm your man: how suppliers gain strategic status in buying companies," Journal of Purchasing and Supply Management, vol. 22, no. 2, pp. 72-81, 2014.

[6] B. Du, S. Guo, X. Huang, Y. Li, and J. Guo, "A Pareto supplier selection algorithm for minimum the life cycle cost of complex product system," Expert Systems with Applications, vol. 42, no. 9, pp. 4253-4264, 2015.

[7] T. L. Saaty, "How to make a decision: the analytic hierarchy process," European Journal Operation-al Research, vol. 48, no. 1, pp. 9-26, 1990.

[8] C.-L. Hwang and K. Yoon, Multiple Attribute Decision Making: Methods and Applications, vol. 186 of Lecture Notes in Economics and Mathematical Systems, Springer, Heidelberg, Germany, 1981.

[9] B. Roy, “Classement et choix en présence de points de vue multiples (La methode ELECTRE)," Revue Française d'Informatique et de Recherche Opérationnelle, vol. 2, no. 8, pp. 57-75, 1968.

[10] D. Tadic, D. D. Milanovic, M. Misita, and B. Tadic, "New integrated approach to the problem of ranking and supplier selection under uncertainties," Proceedings of the Institution of Mechanical Engineers, Part B: Journal of Engineering Manufacture, vol. 225, no. 9, pp. 1713-1724, 2011.

[11] H. A. Guvenir and E. Erel, "Multicriteria inventory classification using a genetic algorithm," European Journal of Operational Research, vol. 105, no. 1, pp. 29-37, 1998. 
[12] A. Aleksić, M. Stefanović, D. Tadić, and S. Arsovski, "A fuzzy model for assessment of organization vulnerability," Measurement, vol. 51, no. 1, pp. 214-223, 2014.

[13] G. J. Klir and T. A. Folger, Fuzzy Sets, Uncertainty and Information, Prentice Hall, Upper Saddle River, NJ, USA, 1988.

[14] W. Pedrycz and F. Gomide, An Introduction to Fuzzy Sets: Analysis and Design, MIT Press, Cambridge, Mass, USA, 1997.

[15] H.-J. Zimmermann, Fuzzy Set Theory-and Its Applications, Kluwer Academic, Boston, Mass, USA, 4th edition, 2001.

[16] P. Kaur and S. Chakrabortyb, "A new approach to vendor selection problem with impact factor as an indirect measure of quality," Journal of Modern Mathematics and Statistics, vol. 1, no. 1, pp. 8-14, 2007.

[17] H. M. Fazel Zarandi, B. I. Türkșen, and S. Saghiri, "Supply chain: crisp and fuzzy aspects," International Journal of Applied Mathematics and Computer Science, vol. 12, no. 3, pp. 423-435, 2002.

[18] B. E. Flores and D. C. Whybark, "Implementing multiple criteria ABC analysis," Journal of Operations Management, vol. 7, no. 1-2, pp. 79-85, 1987.

[19] M.-C. Yu, "Multi-criteria ABC analysis using artificialintelligence-based classification techniques," Expert Systems with Applications, vol. 38, no. 4, pp. 3416-3421, 2011.

[20] A. Hadi-Vencheh and A. Mohamadghasemi, "A fuzzy AHPDEA approach for multiple criteria ABC inventory classification," Expert Systems with Applications, vol. 38, no. 4, pp. 33463352, 2011.

[21] J. Puente, D. de la Fuente, P. Priore, and R. Pino, "Abc classification with uncertain data. A fuzzy model vs. a probabilistic model," Applied Artificial Intelligence, vol. 16, no. 6, pp. 443-456, 2002.

[22] C.-W. Chu, G.-S. Liang, and C.-T. Liao, "Controlling inventory by combining $\mathrm{ABC}$ analysis and fuzzy classification," Computers \& Industrial Engineering, vol. 55, no. 4, pp. 841-851, 2008.

[23] W. Ho, X. Xu, and P. K. Dey, "Multi-criteria decision making approaches for supplier evaluation and selection: a literature review," European Journal of Operational Research, vol. 202, no. 1, pp. 16-24, 2010.

[24] K. Govindan and M. B. Jepsen, "ELECTRE: a comprehensive literature review on methodologies and applications," European Journal of Operational Research, vol. 250, no. 1, pp. 1-29, 2016.

[25] L. H. Alencar, A. T. de Almeida, and D. C. Morais, "A multicriteria group decision model aggregating the preferences of decision-makers based on electre methods," Pesquisa Operacional, vol. 30, no. 3, pp. 687-702, 2010.

[26] G. A. Montazer, H. Q. Saremi, and M. Ramezani, "Design a new mixed expert decision aiding system using fuzzy ELECTRE III method for vendor selection," Expert Systems with Applications, vol. 36, no. 8, pp. 10837-10847, 2009.

[27] A. H. Marbini and M. Tavana, "An extension of the Electre I method for group decision-making under a fuzzy environment," Omega, vol. 39, no. 4, pp. 373-386, 2011.

[28] D. Tadic, A. T. Gumus, S. Arsovski, A. Aleksic, and M. Stefanovic, "An evaluation of quality goals by using fuzzy AHP and fuzzy TOPSIS methodology," Journal of Intelligent \& Fuzzy Systems, vol. 25, no. 3, pp. 547-556, 2013.

[29] D.-Y. Chang, "Applications of the extent analysis method on fuzzy AHP," European Journal of Operational Research, vol. 95, no. 3, pp. 649-655, 1996.

[30] J. M. Merigó and M. Casanovas, "Using fuzzy numbers in heavy aggregation operators," International Journal of Information Technology, vol. 4, no. 4, pp. 267-272, 2008.
[31] S. M. Baas and H. Kwakernaak, "Rating and ranking of multipleaspect alternatives using fuzzy sets," Automatica, vol. 13, no. 1, pp. 47-58, 1977.

[32] D. Dubois and H. Prade, "Decision-making under fuzziness," in Advances in Fuzzy Set Theory and Applications, pp. 279-302, North-Holland, Amsterdam, Netherlands, 1979.

[33] J. C. Pomerol and S. Barba-Romeo, Multicriteria Decision Management: Principles and Practice, Kluwer Nijhoff Publishing, Boston, Mass, USA, 2000.

[34] C.-T. Chen, "Extensions of the TOPSIS for group decisionmaking under fuzzy environment," Fuzzy Sets and Systems, vol. 114, no. 1, pp. 1-9, 2000. 


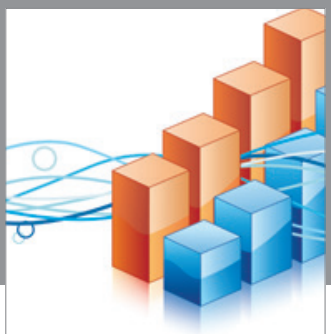

Advances in

Operations Research

vatem alat4

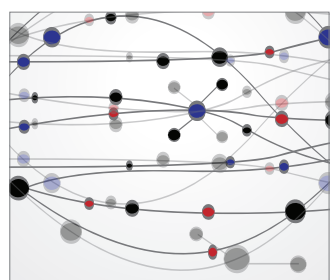

\section{The Scientific} World Journal
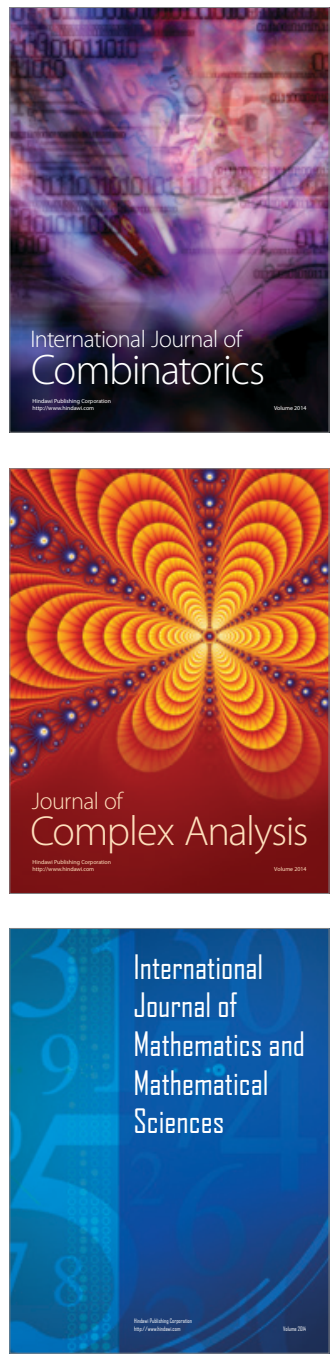
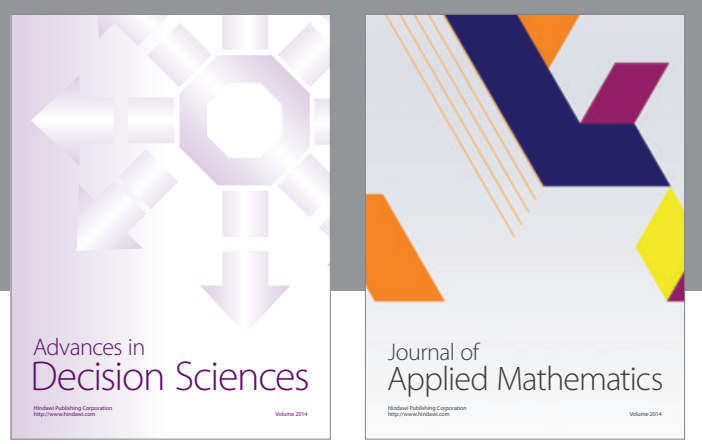

Algebra

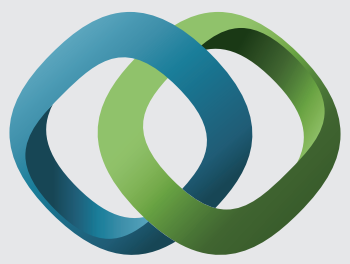

\section{Hindawi}

Submit your manuscripts at

http://www.hindawi.com
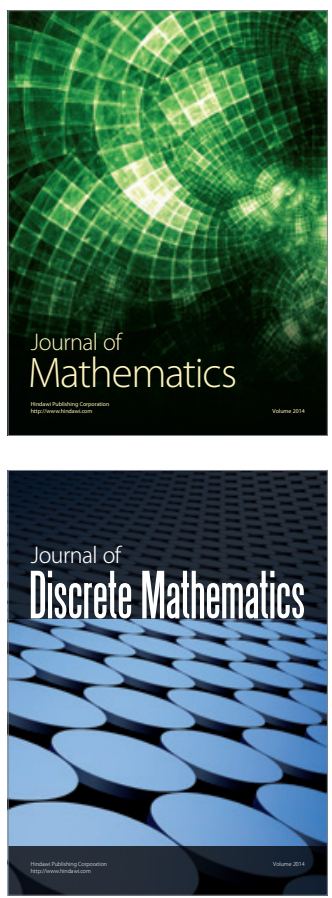

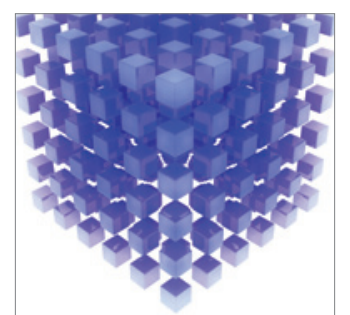

Mathematical Problems in Engineering
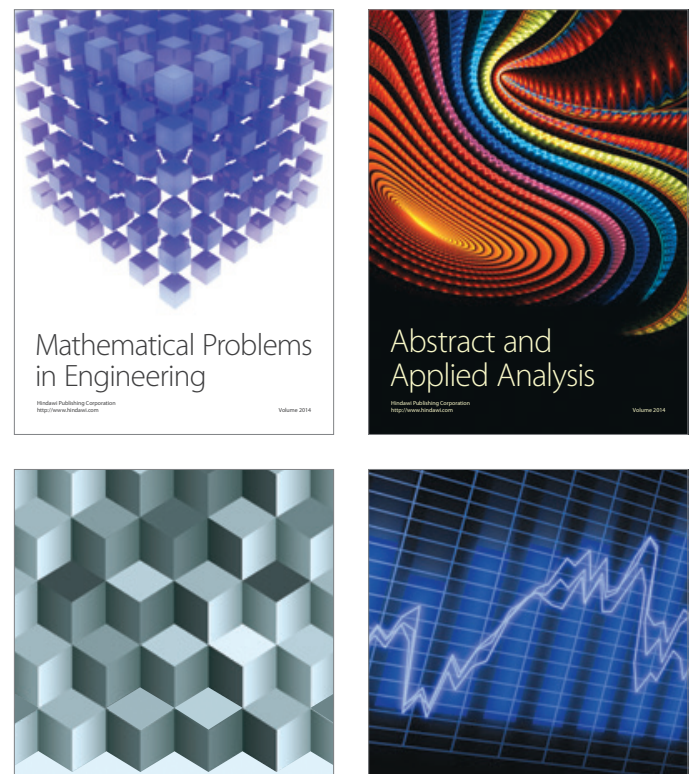

Journal of

Function Spaces

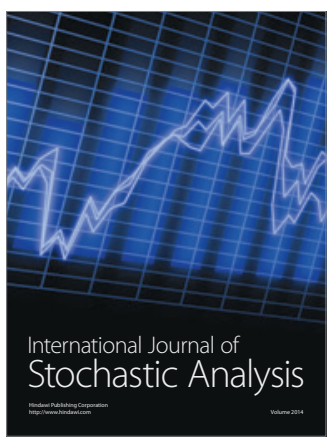

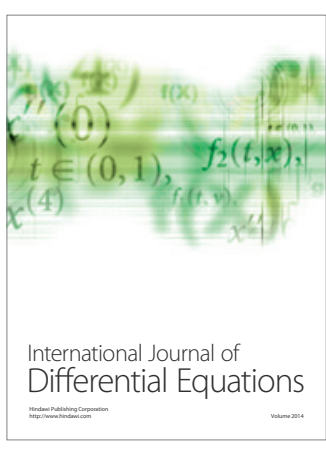
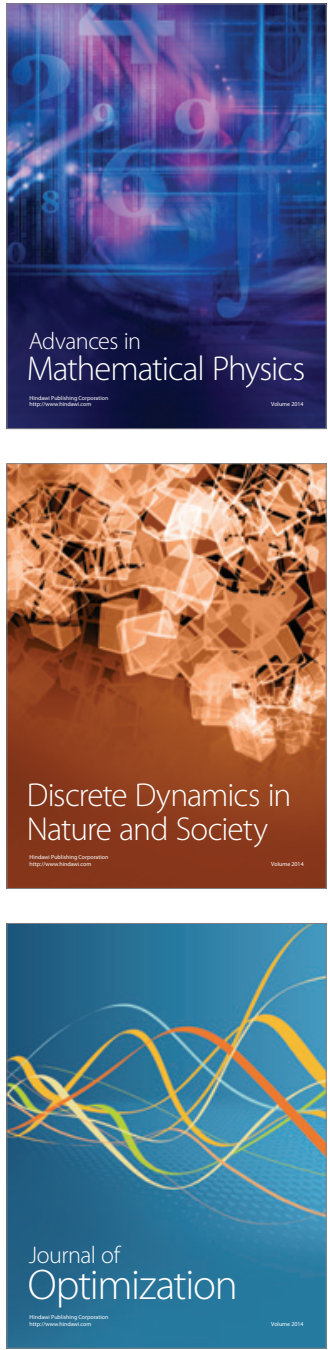